\title{
Can we predict which patients will evolve to chronic kidney disease after nephrectomy for cortical renal tumors?
}

\author{
Fabio Cesar Miranda Torricelli, Alexandre Danilovic, Giovanni Scala Marchini, Alexandre Crippa Sant’Anna, \\ Marcos Francisco Dall'Oglio, Miguel Srougi
}

Division of Urology, Department of Surgery, Hospital das Clinicas, University of Sao Paulo Medical School, Sao Paulo and Instituto do Câncer do Estado de Sao Paulo - ICESP, Sao Paulo, Brazil

\section{ABSTRACT}

Introduction: While some studies show that patients submitted to radical nephrectomy have a higher risk of developing chronic kidney disease (CKD), some studies report that carefully selected living kidney donors do not present a higher risk for CKD. Here, we aim to study predictive factors of CKD after radical nephrectomy.

Materials and Methods: Between January 2006 to January 2010, 107 patients submitted to radical nephrectomy for cortical renal tumors at our institution were enrolled in this study. Demographic data were recorded, modified Charlson-Romano Index was calculated, and creatinine clearance was estimated using abbreviated Modification of Diet in Renal Disease (MDRD) study equation. Pathological characteristics, surgical access and surgical complications were also reviewed. The end-point of the current study was new onset estimated glomerular filtration rate (eGFR) less than 60 and less than $45 \mathrm{~mL} / \mathrm{minute} / 1.73 \mathrm{~m}^{2}$.

Results: Age, preoperative eGFR, Charlson-Romano Index and hypertension were predictive factors of renal function loss, when the end-point considered was eGFR lower than $60 \mathrm{~mL} /$ minute $/ 1.73 \mathrm{~m}^{2}$. Age and preoperative eGFR were predictive factors of renal function loss, when the end-point considered was eGFR lower than $45 \mathrm{~mL} / \mathrm{min}$ ute/1.73 $\mathrm{m}^{2}$. Moreover, each year older increased 1.1 times the risk of eGFR lower than 60 and $45 \mathrm{~mL} /$ minute $/ 1.73 \mathrm{~m}^{2}$. After multivariate logistic regression, only age remained as an independent predictive factor of eGFR loss.

Conclusion: Age is an independent predictive factor of GFR loss for patients submitted to radical nephrectomy for cortical renal tumors.

\section{ARTICLE INFO}

\section{Key words:}

Neoplasms; Nephrectomy;

Renal Cancer; Renal

Insufficiency

Int Braz J Urol. 2012; 38: 637-44

Submitted for publication:

December 13, 2011

Accepted after revision:

May 05, 2012

\section{INTRODUCTION}

Surgical treatment of renal cortical tumors is changing in the last decade. Best management must consider preservation of renal function in order to increase global survival rate. Radical nephrectomy (RN) was considered the gold standard treatment for localized renal cortical tumor (1), however the waste of nephrons causes loss of renal function that is be- ing implicated in the global survival rate decrease. Nephron sparing surgery has specific survival rates similar to those achieved with RN while preserves renal function. Despite the paradigm change, partial nephrectomy represents only 30-65\% of all surgical procedures for renal cortical tumors in tertiary-care centers in the United States (2-4). Low volume centers present an even worse figure and RN remains the standard treatment for most cases (5). 
Advances in imaging exams have led to increased detection of incidental, small $(<4 \mathrm{~cm})$, localized renal cortical tumors. But some tumors cannot be treated by nephron sparing surgery without compromising safety and oncological efficacy, due to a challenging central localization. Even small tumors in the central region may compromise the renal fat around the hilum and despite the low tumor volume, the possibility of a T3 should be considered and therefore RN may still be appropriate in this scenario (6). It has been reported that although experienced surgeons have similar outcomes with radical or partial nephrectomy $(7,8)$, the partial approach can be technically challenging and associated with greater risk of complications, especially if done laparoscopically $(9,10)$.

Huang et al. showed that patients submitted to radical nephrectomy have a higher risk of developing chronic kidney disease (CKD) than patients subjected to partial nephrectomy (11). However, carefully selected living kidney donors do not present a higher risk for CKD (12). Moreover, it has been shown that long-term mortality rate is not significantly increased in living kidney donors (13). These findings led us to looking for patients and tumors features that might influence and could predict which patients will evolve to renal function loss.

In this study, we aim to evaluate demographic data, pathological features, surgical access, and postoperative complications as predictors of CKD after radical nephrectomy for cortical renal tumors.

\section{MATERIALS AND METHODS}

Between January 2006 and January 2010, 180 patients were submitted to RN for cortical renal tumors at our institution. We included only patients treated after 2006 because nephron sparing surgery was already consolidated as the best option for small renal tumors at this time. Patients with end-stage renal disease, bilateral renal tumors or metastases at surgery, and those with less than 12 months of follow-up or incomplete data were excluded from our analysis. Only patients with images of a normal contralateral kidney before surgery were selected. Thus, 107 patients were enrolled in this retrospective study.
Clinical characteristics, including age at surgery, gender, hypertension, cerebrovascular and pulmonary disease, and liver dysfunction were recorded. Modified Charlson-Romano Index $(14,15)$ was calculated as an objective measure of comparing comorbidity among patients. Also, preoperative serum creatinine was recorded and Glomerular Filtration Rate (GFR) was estimated using the abbreviated Modification of Diet in Renal Disease (MDRD) study equation (186 x serum creatinine in $\mathrm{mg} / \mathrm{dL}-1.154 \mathrm{x}$ age in years-0.0203 $\mathrm{x} 0.742$ if female). Pathological characteristics, including size and pT stage were also reviewed. Surgical access (laparoscopic versus open) was analyzed as well as Clavien-Dindo classification of surgical complications (16) used to estimate if postoperative period could have influenced the renal function outcome.

The end-point of the current study was new onset eGFR less than 60 and less than $45 \mathrm{~mL} / \mathrm{min}$ ute/ $1.73 \mathrm{~m}^{2}$, which defines chronic kidney disease more accurately and has been shown to be associated with a significantly higher risk of complications and comorbidity (17-19). Patients had their postoperative eGFR assessed 6 months after surgery and at the end of the follow-up period. Since the main outcome measures were the new onset of GFR lower than 60 or $45 \mathrm{~mL} /$ minute $/ 1.73 \mathrm{~m}^{2}$ after surgery, patients with pre-existing GFR values lower than these two thresholds were not included for outcome analysis.

In order to determinate $p$ values, we used Mann-Whitney test or Student t test for continuous variables and Chi-square test for categorical variables. Because of the small frequency of postoperative complications, Fisher exact test was used for Clavien-Dindo classification. After univariate analysis, multivariate logistic regression was done to determine the real effect of each hypothesized risk factor. All statistical analysis was performed with $\mathrm{p}<0.05$ considered significant.

\section{RESULTS}

Mean (range) age at surgery was 58.5 (25 86) years and $62(57.9 \%)$ patients were male. Mean (range) Charlson-Romano Index was 1.8 (0 - 9) and $43(40.2 \%)$ patients had hypertension. Eighty and four $(78.5 \%)$ were submitted to open radical 
nephrectomy, while 23 (21.5\%) to laparoscopic approach. Demographic data, surgical access (open vs. laparoscopic), surgical pathology, and ClavienDindo classification are summarized in Table- 1 . Mean (range) operative time was 108 (70 - 210) minutes. Mean (range) estimated blood loss was 180 (50 - 700) mL. Mean (range) preoperative eGFR was $72(60-150) \mathrm{mL} /$ minute/ $1.73 \mathrm{~m}^{2}$. Mean (range) follow-up was 32 (18 - 54) months.

After 6 months and at the end of the follow-up period mean eGFR was 58.2 and $57.6 \mathrm{~mL} /$ minute $/ 1.73 \mathrm{~m}^{2}$, respectively. Thirty-two patients had eGFR lower than $60 \mathrm{~mL} /$ minute $/ 1.73 \mathrm{~m}^{2}$ six months after surgery, while 14 patients had eGFR lower than $45 \mathrm{~mL} /$ minute $/ 1.73 \mathrm{~m}^{2}$ at the same period. At the end of the follow-up, 29 patients had eGFR lower than $60 \mathrm{~mL} /$ minute $/ 1.73 \mathrm{~m}^{2}$, because three presented a small improvement in the renal function, and 16 patients had eGFR lower than 45 $\mathrm{mL} /$ minute $/ 1.73 \mathrm{~m}^{2}$.

When the end-point considered was eGFR lower than $60 \mathrm{~mL} /$ minute $/ 1.73 \mathrm{~m}^{2}$, age $(\mathrm{p}=0.002)$, Charlson-Romano Index $(\mathrm{p}=0.01)$ and hypertension $(p=0.04)$ were significant predictors of renal

Table 1 - Demographic data, surgical access, surgical pathology, and Clavien-Dindo Classification.

\begin{tabular}{|c|c|c|}
\hline Mean (range) age & \multicolumn{2}{|c|}{$58.5(25$ - 86) years } \\
\hline Median age & \multicolumn{2}{|c|}{59 years } \\
\hline Gender & $62(57.9 \%)$ male & $45(42.1 \%)$ female \\
\hline Mean (range) Charlson Index & \multicolumn{2}{|c|}{$1.8(0-9)$} \\
\hline Median Charlson Index & \multicolumn{2}{|c|}{1} \\
\hline Hypertension & $43(40.2 \%)$ yes & $64(59.8 \%)$ no \\
\hline Surgical access & $84(78.5 \%)$ open & $23(21.5 \%)$ laparoscopic \\
\hline \multirow[t]{2}{*}{ Pathology } & \multicolumn{2}{|c|}{$97(90.6 \%)$ clear cell carcinoma } \\
\hline & \multicolumn{2}{|c|}{$10(9.4 \%)$ chromophobe carcinoma } \\
\hline \multirow[t]{4}{*}{ Pathological stage } & pT1 & $37(34.6 \%)$ \\
\hline & pT2 & $25(23.4 \%)$ \\
\hline & pT3 & $37(34.6 \%)$ \\
\hline & pT4 & $8(7.5 \%)$ \\
\hline \multirow[t]{6}{*}{ Clavien-Dindo classification } & 0 & $100(93.5 \%)$ \\
\hline & 1 & $4(3.7 \%)$ \\
\hline & 2 & $1(0.9)$ \\
\hline & 3 & $2(1.9 \%)$ \\
\hline & 4 & 0 \\
\hline & 5 & 0 \\
\hline
\end{tabular}


function loss at six months of follow-up. At the end of that period, these factors and preoperative eGFR ( $p=0.02$ ) were significant predictors of renal function loss (Table-2). Moreover, for each year older, the risk of eGFR lower than $60 \mathrm{~mL} /$ minute $/ 1.73 \mathrm{~m}^{2}$ increased 1.1 times, and for each point acquired in the Charlson-Romano Index, the risk of eGFR lower than $60 \mathrm{~mL} /$ minute $/ 1.73 \mathrm{~m}^{2}$ increased 1.24 times. However, after multivariate logistic regression, only age $(p=0.005)$ remained as an independent predict factor of eGFR loss.

\section{DISCUSSION}

This study presents original and relevant data. Multivariate logistic regression shows that age is the only predictor related to renal function loss after radical nephrectomy (OR: 1.1, 95\% CI 1.04-1.15). Moreover, the risk of eGFR lower than 60 or $45 \mathrm{~mL} /$ minute $/ 1.73 \mathrm{~m} 2$ after $\mathrm{RN}$ increases $10 \%$ for each year older.

The 3-year probability of absence of new onset of GRF lower than $60 \mathrm{~mL} / \mathrm{min}$ per $1.73 \mathrm{~m}^{2}$ is

Table 2 - Predictive factors of development of chronic kidney disease following radical nephrectomy (univariate analysis).

\begin{tabular}{|c|c|c|c|c|}
\hline & \multicolumn{2}{|c|}{$\mathrm{eGFR}<60 \mathrm{~mL} / \mathrm{min} / 1.73 \mathrm{~m}^{2}$} & \multicolumn{2}{|c|}{$\mathrm{eGFR}<45 \mathrm{~mL} / \mathrm{min} / 1.73 \mathrm{~m}^{2}$} \\
\hline & 6 months & End & 6 months & End \\
\hline Age & $p=0.002$ & $p<0.001$ & $p=0.003$ & $p=0.001$ \\
\hline Gender & $p=0.61$ & $p=0.07$ & $p=0.51$ & $p=0.16$ \\
\hline Preoperative eGFR & $p=0.23$ & $p=0.02$ & $P=0.01$ & $P<0.001$ \\
\hline Charlson-Romano Index & $p=0.01$ & $p=0.01$ & $p=0.08$ & $p=0.09$ \\
\hline Hypertension & $p=0.05$ & $p=0.04$ & $p=0.72$ & $p=0.11$ \\
\hline Surgical access & $p=0.67$ & $p=0.41$ & $p=0.96$ & $p=1.00$ \\
\hline Pathological stage & $p=0.17$ & $p=0.44$ & $p=0.65$ & $p=0.41$ \\
\hline Clavien-Dindo classification & $p=1.00$ & $p=0.63$ & $p=0.21$ & $p=0.32$ \\
\hline $95 \% \mathrm{Cl}$ & & & & \\
\hline
\end{tabular}

When the end-point considered was eGFR lower than $45 \mathrm{~mL} /$ minute $/ 1.73 \mathrm{~m}^{2}$, age $(\mathrm{p}=0.003)$ and preoperative eGFR $(p=0.01)$ were predictors of renal function loss at six months of follow-up. Charlson-Romano Index ( $p=0.08)$ appeared to be higher in patients with eGFR loss. All these findings persisted until the end of the follow-up period (Table-2). Again, for each year older, the risk of eGFR lower than $45 \mathrm{~mL} /$ minute $/ 1.73 \mathrm{~m}^{2}$ increased 1.1 times. After multivariate logistic regression, age remained $(p=0.001)$ as an independent predictor factor of eGFR loss.
$80 \%$ and 35\% after partial and radical nephrectomy, respectively. The corresponding values for GFR lower than $45 \mathrm{~mL} / \mathrm{min}$ per $1.73 \mathrm{~m}^{2}$ are $95 \%$ and $64 \%$ (11). However, partial nephrectomy is not always possible due to large renal tumors, central localized tumors, or in some cases, when performed mainly in small centers, because inexperienced surgeons are not used to the procedure. In these situations, it is very important for the surgeon to predict which patients are potential candidates to radical nephrectomy without compromising GFR outcome and patient survival. Even in those cases 
where radical nephrectomy is the only option, it is very beneficial to know the risk of new onset of CKD to prepare patients and medical care team to this unpleasant event.

Outcome data from transplantation studies (20-22) have long supported that CKD after total nephrectomy is not a major concern in patients with two equivalent functioning kidneys and normal preoperative concentration of serum creatinine, since donors submitted to nephrectomy do not show decrease of their kidney function, kidney failure needing dialysis, or death. However, this is not observed in patients submitted to RN for cortical renal tumors. These findings encouraged us to look for which factors could influence and predict which patients would evolve to renal function loss.

Yokoyama et al. (23) retrospectively studied 416 patients submitted to nephrectomy and after univariate and multivariate analysis radical nephrectomy was an independent risk factor for new onset eGFR less than $60 \mathrm{~mL} / \mathrm{min}$ per $1.73 \mathrm{~m}^{2}$ (HR 3.19, 95\% CI 1.72 - 6.75) but not for new onset eGFR less than $45 \mathrm{~mL} / \mathrm{min}$ per $1.73 \mathrm{~m}^{2}$. Age at surgery and preoperative eGFR were independent risk factors for new onset less than $45 \mathrm{~mL} / \mathrm{min}$ per $1.73 \mathrm{~m}^{2}$. Barlow et al. (24) presented similar results in another retrospectively study with 209 patients submitted to nephrectomy and with preoperative eGFR higher than $60 \mathrm{~mL} / \mathrm{min}$ per $1.73 \mathrm{~m}^{2}$. On multivariate analysis, preoperative CKD and procedure (radical versus partial) were independent predictors of new onset renal insufficiency. In this study, hypertension was an independent predictor of CKD upstage. Suer et al. (25) studied the longterm impact of hypertension and diabetes mellitus on GFR in the long term in 488 patients submitted to nephrectomy and noted that hypertension was associated with new onset of chronic renal failure only in the radical nephrectomy group (HR 1.39, 95\% CI 1.02 - 1.89).

In our study, age, preoperative eGFR, and hypertension were related to renal function loss, corroborating literature data. Our study presents an original contribution that may improve the care of patients that suffer from renal tumors and are going to be submitted to RN. We found that for each year older, the risk of eGFR lower than 60 or $45 \mathrm{~mL} /$ minute/ $1.73 \mathrm{~m}^{2}$ after RN increases 10\%.

In partial nephrectomy, predicting factors of lower GFR were well studied in a large cohort of 1169 patients by Lane et al. (26). Lower preoperative GFR, solitary kidney, older age, tumor size and longer ischemic interval were all predicting factors of bad renal function outcome. However, unfortunately, this paper did not study patient's comorbidities and did not evaluate which of these factors could predict CKD in patients that are not candidate to partial nephrectomy. Santos Arrontes et al. (27) studied the survival rate after nephrectomy for clear cell carcinoma according to the Charlson comorbidity index in 192 patients submitted to nephrectomy. They reported that tumor stage and comorbidity (Charlson greater than two) were prognostic factors after one, five and ten years of follow-up. The authors concluded that the comorbidity index should be applied in daily clinical practice to assess the best therapeutic option for patients. In our study, the Charlson-Romano Index was related to renal function loss, and for each point acquired in the Charlson-Romano Index, the risk of eGFR lower than $60 \mathrm{~mL} / \mathrm{min}$ ute/ $1.73 \mathrm{~m}^{2}$ increased 1.24 times. It appears that Charlson-Romano Index is an important factor that should be used in patients that will be submitted to nephrectomy.

Our study has some limitations. It includes a small sample, which may have affected our multivariate analysis, and as a retrospective study, patients were not randomly assigned to open or laparoscopic procedure, which means that the choice of surgical technique has been biased by the surgeon's preference. However, we may note that partial nephrectomy, when technically feasible, must be performed in older patients. In our study, as we are a tertiary reference service, we have treated complex cases and/or central localized mass, leading to a high prevalence of $\mathrm{RN}$ and open approach. Another limitation is that the median follow-up period of 32 months may not have been long enough to draw conclusions on long-term postoperative renal function. Maybe in a future publication this doubt can be resolved. Large studies with longer follow-up are needed to evaluate long-term renal function after radical nephrectomy. 


\section{CONCLUSIONS}

Age is an independent predicting factor of GFR loss for patients submitted to radical nephrectomy for cortical renal tumors. Each year old increases $10 \%$ the risk of CKD after radical nephrectomy. Preoperative eGFR and CharlsonRomano Index also should be evaluated before nephrectomy.

\section{ABBREVIATIONS}

RN - Radical Nephrectomy

CKD - Chronic Kidney Disease

GFR - Glomerular Filtration Rate

MDRD - Modification of Diet in Renal Disease

\section{CONFLICT OF INTEREST}

None declared.

\section{REFERENCES}

1. Robson CJ, Churchill BM, Anderson W: The results of radical nephrectomy for renal cell carcinoma. J Urol. 1969; 101: 297-301.

2. Uzzo RG, Wei JT, Hafez K, Kay R, Novick AC: Comparison of direct hospital costs and length of stay for radical nephrectomy versus nephron-sparing surgery in the management of localized renal cell carcinoma. Urology. 1999; 54: 994-8.

3. Russo P: Open partial nephrectomy: an essential contemporary operation. Nat Clin Pract Urol. 2006; 3: 2-3.

4. Scherr DS, Ng C, Munver R, Sosa RE, Vaughan ED Jr, Del Pizzo J: Practice patterns among urologic surgeons treating localized renal cell carcinoma in the laparoscopic age: technology versus oncology. Urology. 2003; 62: 1007-11.

5. Muruganandham K, Mandhani A: Chronic kidney disease and small renal tumors: What urologists should know? Indian J Urol. 2009; 25: 543-4.

6. Bertini R, Roscigno M, Freschi M, Strada E, Petralia G, Pasta $A$, et al.: Renal sinus fat invasion in pT3a clear cell renal cell carcinoma affects outcomes of patients without nodal involvement or distant metastases. J Urol. 2009; 181: 2027-32.

7. Stephenson AJ, Hakimi AA, Snyder ME, Russo P: Complications of radical and partial nephrectomy in a large contemporary cohort. J Urol. 2004; 171: 130-4.
8. Gill IS, Matin SF, Desai MM, Kaouk JH, Steinberg A, Mascha $\mathrm{E}$, et al.: Comparative analysis of laparoscopic versus open partial nephrectomy for renal tumors in 200 patients. J Urol. 2003; 170: 64-8.

9. Ching CB, Li J, Gill IS, Simmons MN: Functional and oncologic outcomes of bilateral open partial nephrectomy versus bilateral laparoscopic partial nephrectomy. J Endourol. 2011; 25: 1193-7.

10. Chung BI, Lee UJ, Kamoi K, Canes DA, Aron M, Gill IS: Laparoscopic partial nephrectomy for completely intraparenchymal tumors. J Urol. 2011; 186: 2182-7.

11. Huang WC, Levey AS, Serio AM, Snyder M, Vickers AJ, Raj GV, et al:: Chronic kidney disease after nephrectomy in patients with renal cortical tumours: a retrospective cohort study. Lancet Oncol. 2006; 7: 735-40.

12. Ibrahim HN, Foley R, Tan L, Rogers T, Bailey RF, Guo H, et al.: Long-term consequences of kidney donation. $\mathrm{N}$ Engl J Med. 2009; 360: 459-69.

13. Segev DL, Muzaale AD, Caffo BS, Mehta SH, Singer AL, Taranto $S E$, et al.: Perioperative mortality and long-term survival following live kidney donation. JAMA. 2010; 303: 959-66.

14. Charlson ME, Pompei P, Ales KL, Mackenzie CR: A new method of classifying prognostic comorbidity in longitudinal studies: development and validation. J Chronic Dis. 1987; 40: 373-83.

15. Romano PS, Roos LL, Jollis JG: Adapting a clinical comorbidity index for use with ICD-9-CM administrative data: differing perspectives. J Clin Epidemiol. 1993; 46: 1075-9; discussion 1081-90.

16. Clavien PA, Barkun J, de Oliveira ML, Vauthey JN, Dindo D, Schulick RD, et al.: The Clavien-Dindo classification of surgical complications: five-year experience. Ann Surg. 2009; 250: 187-96.

17. Go AS, Chertow GM, Fan D, McCulloch CE, Hsu CY: Chronic kidney disease and the risks of death, cardiovascular events, and hospitalization. N Engl J Med. 2004; 351: 1296-305. Erratum in: N Engl J Med. 2008;18: 4.

18. Anavekar NS, McMurray JJ, Velazquez EJ, Solomon SD, Kober L, Rouleau JL, et al.: Relation between renal dysfunction and cardiovascular outcomes after myocardial infarction. N Engl J Med. 2004; 351: 1285-95.

19. Murthy K, Stevens LA, Stark PC, Levey AS: Variation in the serum creatinine assay calibration: a practical application to glomerular filtration rate estimation. Kidney Int. 2005; 68: 1884-7.

20. Najarian JS, Chavers BM, McHugh LE, Matas AJ: 20 years or more of follow-up of living kidney donors. Lancet. 1992; 340: 807-10.

21. Fehrman-Ekholm I, Dunér F, Brink B, Tydén G, Elinder CG: No evidence of accelerated loss of kidney function in living kidney donors: results from a cross-sectional follow-up. Transplantation. 2001; 72: 444-9. 
22. Fehrman-Ekholm I, Elinder CG, Stenbeck M, Tydén G, Groth CG: Kidney donors live Ionger. Transplantation. 1997; 64: 976-8.

23. Yokoyama M, Fujii $Y$, limura $Y$, Saito K, Koga F, Masuda $H$, Kawakami S, Kihara K: Longitudinal change in renal function after radical nephrectomy in Japanese patients with renal cortical tumors. J Urol. 2011; 185: 2066-71.

24. Barlow LJ, Korets R, Laudano M, Benson M, McKiernan $\mathrm{J}$ : Predicting renal functional outcomes after surgery for renal cortical tumours: a multifactorial analysis. BJU Int. 2010; 106: 489-92.

25. Süer E, Burgu B, Gökce MI, Türkölmez K, Bedük Y, Baltaci S: Comparison of radical and partial nephrectomy in terms of renal function: a retrospective cohort study. Scand J Urol Nephrol. 2011; 45: 24-9.
26. Lane BR, Babineau DC, Poggio ED, Weight CJ, Larson BT Gill IS, et al.: Factors predicting renal functional outcome after partial nephrectomy. J Urol. 2008; 180: 2363-8; discussion 2368-9.

27. Santos Arrontes D, Fernández Aceñero MJ, García González JI, Martín Muñoz M, Paniagua Andrés P: Survival analysis of clear cell renal carcinoma according to the Charlson comorbidity index. J Urol. 2008; 179: 857-61.

Correspondence address:

Dr. Fábio César Miranda Torricelli Av. Vereador Jose Diniz, 3300 / 208 Sao Paulo, SP, 04604-006, Brazil Fax:+ 5511 5533-4900

E-mail: fabio_torri@yahoo.com.br 


\section{EDITORIAL COMMENT}

This is an interesting retrospective study about possible prediction factors (age, preoperative renal function, Charlson-Romano-Index and hypertension) for chronic kidney disease (CKD) in 107 patients submitted to radical nephrectomy (RN). Exclusion criteria were end stage renal disease, bilateral renal tumors, metastases at surgery, less than 12 months of follow-up and an abnormal contralateral kidney in imaging studies.

The predictive factors of kidney dysfunction after RN were age, preoperative renal function, Charlson-Romano-Index and hypertension, when the end point considered estimated was glomerular filtration rate (eGFR) lower than $60 \mathrm{~mL} /$ $\mathrm{min} / 1.73 \mathrm{~m} 2$. When the end point considered was eGFR lower than $45 \mathrm{~mL} / \mathrm{min} / 1.73 \mathrm{~m} 2$, only age and preoperative eGFR remained as predictive factors. Age remained as an independent predictor factor of eGFR loss after multivariate logistic regression.

An important limitation of this paper is the short period of follow-up (18-54 months), as the authors mentioned at Discussion. Furthermore, $34.6 \%$ of the patients had small renal tumors (pT1), and missing was information on what percentage of patients was potentially eligible for partial nephrectomy (PN) but underwent RN instead. The under use of PN can easily be found in other studies, despite evidence of equivalent oncologic outcomes and an increased likelihood of developing CKD and cardiovascular comorbidity associated with $\mathrm{RN}$ (1-3).

Hence, RN should still be discouraged for patients with small renal tumors amenable to partial nephrectomy, including the elderly. As stated by the paper's conclusion, age is undoubtedly a predictive factor for CKD after RN. Lowrance et al. (4) evaluated age and procedure type and found no evidence indicating an increased risk of nephronsparing surgery complications with advancing age. On the other hand, in this group of patients, active surveillance can also be used and safely avoid surgery for Stage T1a renal masses (5).

The title is very attractive, but the question still remained without a definite answer ("Can we predict which patients will evolve to chronic kidney disease after nephrectomy for cortical tumors?"). As pointed by the authors, maybe a future study with a longer follow-up and also with more strict criteria for the indication for RN could contribute even more to this issue.

\section{REFERENCES}

1. Russo P, Huang W: The medical and oncological rationale for partial nephrectomy for the treatment of $\mathrm{T} 1$ renal cortical tumors. Urol Clin North Am. 2008; 35: 635-43.

2. Huang WC, Levey AS, Serio AM, Snyder M, Vickers AJ, Raj GV, et al:: Chronic kidney disease after nephrectomy in patients with renal cortical tumours: a retrospective cohort study. Lancet Oncol. 2006; 7: 735-40.

3. Huang WC, Elkin EB, Levey AS, Jang TL, Russo P: Partial nephrectomy versus radical nephrectomy in patients with small renal tumors--is there a difference in mortality and cardiovascular outcomes? J Urol. 2009; 181: 55-61; discussion 61-2.
4. Lowrance WT, Yee DS, Savage C, Cronin AM, O'Brien MF, Donat SM, et al.: Complications after radical and partial nephrectomy as a function of age. J Urol. 2010; 183: 1725-30.

5. Lane BR, Abouassaly R, Gao T, Weight CJ, Hernandez AV, Larson BT, et al.: Active treatment of localized renal tumors may not impact overall survival in patients aged 75 years or older. Cancer. 2010; 116: 3119-26.

Dr. Daniel Lima Xavier Clinical Hospital of the Federal University of Minas Gerais Av. Prof. Alfredo Balena, 110, Santa Efigência Belo Horizonte, MG, 30130-100, Brazil E-mail:limadx@hotmail.com 